\title{
Research on Reading Cultures in Chinese Colleges and Universities
}

\author{
Huaping Gong ${ }^{1, *}$, Hongxin Gao $^{2}$ \\ ${ }^{1}$ Information management department ,Information engineering college ,Nanchang University, 999 \\ Xuefu Avenue, HongGutan District ,Nanchang City ,Jiangxi Province, China
}

Keywords: reading cultures, colleges and universities, constructions, reading habits, statistics, current status, proposals

Abstract: This paper is an in-depth and comprehensive research on the reading cultures in colleges and universities in China, which includes its current status, problems and proposals about its construction.

\section{Introduction}

In August 2013, the latest statistics, Beijing University Library where owns more than 100 million books that is the equivalent of three National library or fifteen Capital library, but no one has expressed interest in it. The article Worrying about: Chinese, who never reads which written by foreign friends who settle in Shanghai, was reprinted frequently. Chinese flowers more leisure time in micro-blog and wechat, more and more people give up the habit of reading.

Reading is an important way to explore the world, find the world and understand the world, is not only a multi-level process to obtain information from a variety of ways, but also a fundamental way of the development of human culture.

Hu Jintao's important speech in the 100 years anniversary of Tisinghua University which put the cultural inheritance and innovation into one of the important functions of colleges and universities, clearly pointed out that to improve the quality of Higher Education, we must vigorously promote the inheritance and innovation of culture. At different levels of Education, university education is the link between social and school, reading culture construction in colleges and universities is bound to lead the whole society to construct and promote cultural reading, it is an important way to promote the national development and social harmony.

\section{Investigation and Analysis}

\section{Research Object and Research Methods}

This research chooses Jiangxi Province where four representative universities were investigation of college students' cultural reading. Survey was conducted in 2013, July to 2013, September, a random survey of four well-known colleges and universities in Jiangxi Province. The survey, including Nanchang University, Jiangxi University of Finance and Economics, East China Transportation University, four University Nanchang aviation university students, is a total of 579 questionnaires.

The survey is divided into 2 kinds of paper questionnaire and Internet questionnaire. Questionnaire design content includes characteristic information, the basic situation of the individual reading contents, motives and means of reading environment, reading and buying books and network reading etc, which is a total of 48 multiple-choice questions. Subjective question 1.The survey takes the form of online questionnaire to give priority to, online results and paper questionnaires summary statistics and analysis. Among 367 online questionnaire and 212 questionnaires paper, there is the recovery of 548 valid questionnaires and the efficiency is $94.65 \%$. The sample sex male to female ratio was 372 boys, accounted for 67.9\%, 176 girls, accounted for 32.1\%, 203 city students, accounted for 37\%, Rural students 345, accounted for 63\%, 310 Science \&engineering students, accounted for 56.6\%, 144 Economic and trade class student, accounted for 26.2\%, 94 Humanities students, accounted for $17.2 \%$. 
Research method is mainly through the data statistics, the usage of statistical knowledge description and analysis, after investigation and verification and data entry, scientific analysis of the qualitative and quantitative results, full range of present reading situation of university culture, the construction of reading culture reflect the real situation and development trend, On the construction of reading culture puts forward constructive suggestions and corresponding measures to guide, which hope to promote reading culture construction in colleges and universities.

\section{Analysis of the Status Quo}

(1) Spare time is rarely used for reading

Through the statistics and the questionnaires, more than $84 \%$ of the students think their spare time is enough for the Internet, chat or listen to music, club activities respectively $81.4 \%$ 、 $68.6 \%$ 、 49.5\% , part-time job, shopping, sports, other proportional to $32.1 \%$ 、 $19.5 \%$ 、 $18.4 、 15.9 \%$. Compared to the Internet, chat or listen to music, community activities and the proportion of part-time job, the proportion of reading extracurricular books only holds $26.8 \%$. The Internet high proportion is more than three times of reading extracurricular books ratio . (See Figure 1)

Proportion

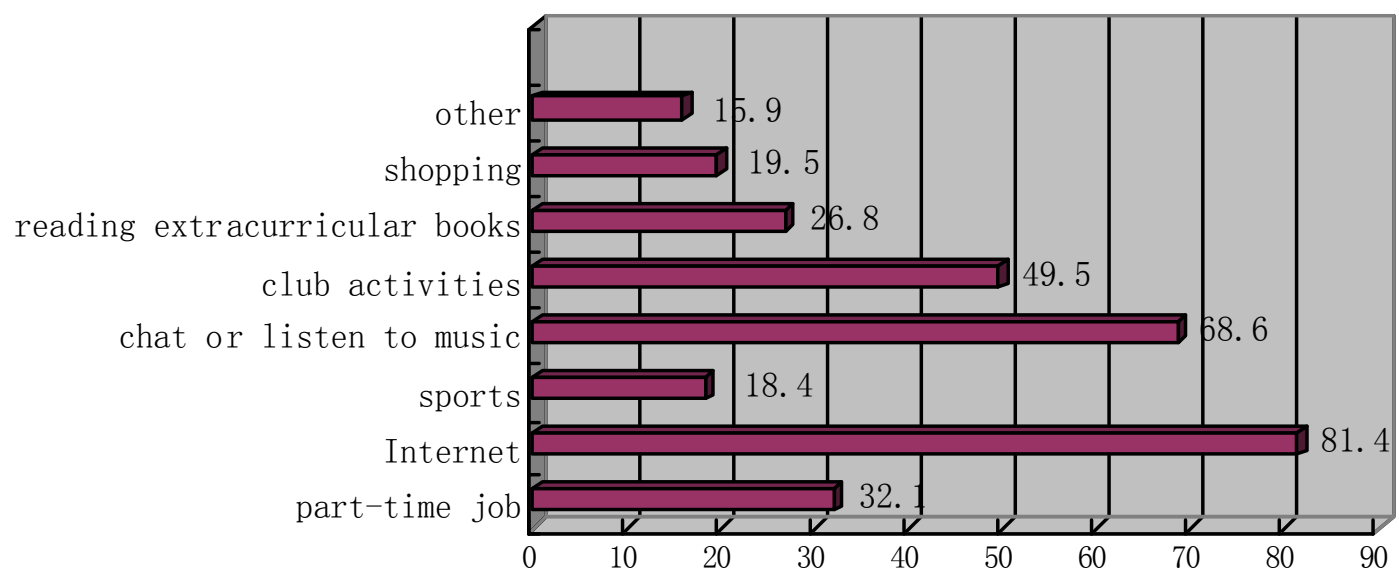

Fig. 1 Arrangement of spare time for University student

Only $26.8 \%$ of the students is in extracurricular reading books, and only $11.5 \%$ of the students have extracurricular reading books every day, $71.4 \%$ of the students choose the "sometimes, seldom, hardly" which means their reading time is limited to 1 hours to 2 hours. Network impact reading is a global phenomenon, but reading habits of Chinese people is very low, especially for college students who have plenty of spare time, but only a very small proportion of them like reading extracurricular books, now the situation of reading culture construction in colleges and universities is worrying, reading culture development and reading interest has become a serious thing which can not be ignored [1].

(2) No suitable reading environment

The results obtained in this investigation, $27.9 \%$ of the students choose to read a book in the library and reading room, $54.7 \%$ of the students choose to read a book in the dormitory, $11.3 \%$ of the students choose to read a book in the classroom, $6.1 \%$ of the students choose the other place to read a 
book. Other places relatively dormitory and library and reading room is occupied small proportion of students, so the main place of reading is still the dormitory , library and the reading room.

The main reason of impact reading which $72.1 \%$ of the students think that is no reading atmosphere, then $42.8 \%$ of the students think that is no enough time for reading, cannot find the reading interest accounted for $21.6 \%$, affected by the surrounding classmates and friends and that its not good at reading respectively accounted for $22.5 \%$ and $16.2 \%$, think there are too many types of that book accounted for $11.4 \%$. The vast majority of students are not because of lacking of interest in reading thus give up reading, but lacking of a good reading environment. According to the survey, in the never read book crowd, $41 \%$ of people are too busy to have no time to read, $39.9 \%$ of the people have no habit of reading. The lack of reading environment has become the primary factor of reading culture in colleges and universities weak[2], with the development of modern social, life rhythm speeding up, influences of employment pressure on college students is closely related to the same.

(3) The ideas from friends become the orientation of standard reading

Among the influence factors of college students on reading books, most students choose the recommendation of a friend, accounted for $61.1 \%$, the second is the teacher's recommendation, accounted for $25.6 \%$, friends on the impact of reading was significantly higher than that of teachers' impact on reading, which shows that the selection effect from teachers works much lower than friends. $81.2 \%$ of the students answered the teacher had to recommend books, so the teacher for reading culture construction in Colleges and universities is forward-looking, but college students think the books which teacher recommended lack of interest, during the conflict, we should pause for thought. Library as the main place of reading in factors is only $11.3 \%$, not playing a leading role of Library Culture, which is clearly contrary to the original intention of education. Because the construction of library culture should be paid more attention, let the library play benchmarking role in guiding reading culture. ( See Figure 2)
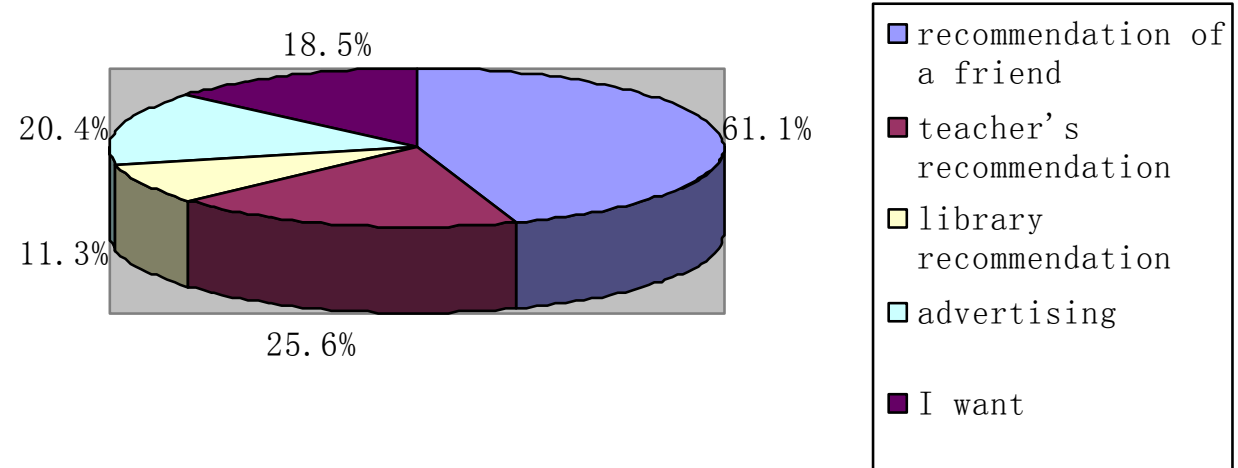

Fig. 2 Influence factors of college students choose reading books

(4) Reading activity is the key to reading interest reduction

According to the survey, $78.6 \%$ of the students answered only a small amount of reading activities are held in their schools. That being Interest in reading is the power, is the key to Reading culture development, but looking from the result, it makes us feel this key has been neglected. The relevant departments should pay more attention to college students' interest in reading, conduct more reading related activities [3], stimulate students' interest in reading, and provide strong support for reading culture construction in colleges and universities.

(5) Jobs become the standard motivation of reading.

On reading motivation, results show that $74.9 \%$ students are preparing for the job, $60.7 \%$ of the students aim to learn the knowledge, $43.2 \%$ of the students are for entertainment, choosing to improve accomplishment of students accounted for $36.2 \%$, 34\% of the students aim to understand fashion, $29.1 \%$ of the students choose the pro forma, $29 \%$ of the students are used to relieve the pressure of spirit, $8.6 \%$ of the students aim to scientific research, from this point of view, the job has become standard reading motivation orientation of colleges and Universities, learning knowledge and 
entertainment also occupy a certain position. When college students are under pressure in the social life, facing the employment, they have to continue to expand their knowledge, so the job has become the main motivation of college students' reading, the relevant departments should make corresponding measures to promote the development of education and reading culture [4].

(6) Network reading as a new way of reading

With the development of the network, amount of information resources in Shanghai Network provide a lot of convenience for human life. Now the network has become the main way for college students to obtain information, ways to obtain information, network for $86.5 \%$ students, compared to the Internet, magazines and newspapers are only accounted for $49.6 \%$. The college students got information from the Internet instead of entertainment nowadays, 38.4\% students are in order to expand the knowledge, reading e-books students accounted for $28.7 \%$. The network has become an indispensable part of College Students to promote the reading cultural construction [5].

The network reading has the following advantages: $56.8 \%$ of the students think that it has strong interaction, to save money, easy to understand, easy to carry respectively accounted for $21.6 \%$, $14.7 \%, 8.1 \%$. The network reading as a new reading culture, must undergo an immature to mature process, it has many advantages, the mass of information and convenient search, which has become a mainstream way of obtaining information. Compared to the traditional sense of reading, Network reading is more likely to be chosen to promote the development of the social culture of reading university . (See Figure 3)

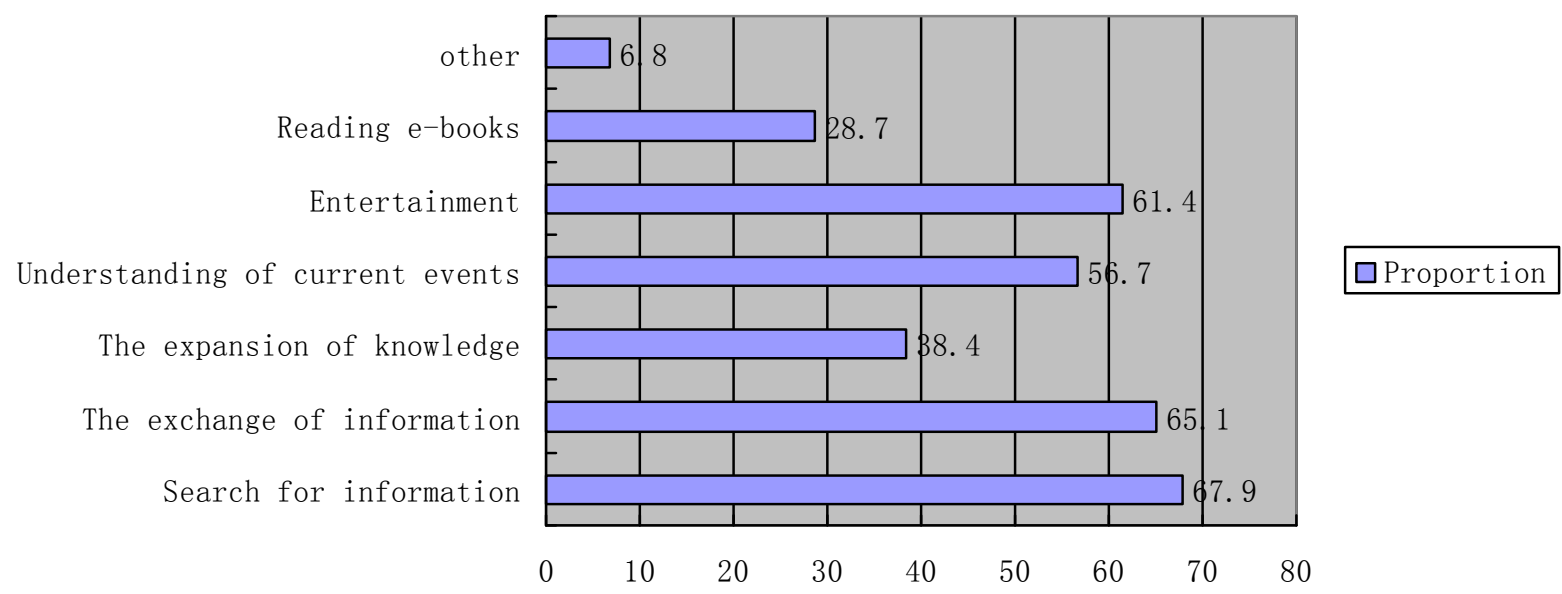

Fig. 3 The main purpose of College Students Internet

\section{Summary}

According to the research, the situation of reading culture is good, but there are still many problems to be solved. To deal with these problems, it is not only relying on a clear plan for reading, but also the relevant departments to study.

(1) The state promotes

Eighteen big reports of the party put forward to promote socialist cultural construction. Many countries take the college reading into work, combine with the students' academic, the number of books are prescribed to be read, or he can not graduate. The reading of the law aims to create a good reading environment for college students. At the same time with the law, we should try to avoid the utilitarian thought that the contemporary college students have and the bad atmosphere in campus.

(2) The college guide to stimulate interest in reading

The active reading activities can dig out wisdom and charming qualities of components. According to the characteristics of students, school organizes lively reading activities to attract students to participate in. And the student union of the university can form the reader club to talk about reading 
and also to exchange ideas, initiate and recommend other students to read good books. This is guiding students to strong measures of high quality reading, Promote the healthy development of University Cultural Reading. The teacher's behavior may influence the choice of them as a guide.

(3) The library broadens the concept of resource sharing

The library can provide good information resources which let the students find their desired knowledge. Bright and spacious areas, the books are clean and tidy, which can let the students have a reading for enjoyment. With today's social and cultural development, the library should also broaden the ideato construct a new mode of Internet resource sharing.

A do not pay attention to reading is the lack of reading ability for students. Without a good reading atmosphere in the university equals to no life, no hope of university, a do not pay attention to reading society is a superficial no spiritual pillar of society "Reading is the mother of study", only have a good reading atmosphere in the campus, then will we make the better construction and development of the school. Only the whole society love reading, then will we own a bright future ahead.

\section{Acknowledgement}

This article is the research results of 2013 Jiangxi Province student innovation training project (201310403068).

\section{Literature References}

[1] Yu Jinli. The survey of the tendency of Shanghai college students buying and reading books [J]. Publishing research,2006, (4):19-22.

[2] Sun Yuemu,Zhang Weichi. Chinese 30 years reading history of soul [M]. Jiangxi Education Publishing House,2009.

[3] Hao Zhensheng,Chen Wei. Blue book of nationwide reading movement (first volume) [M] Haitian Publishing House, 2009.

[4] Cui Chun. Higher Vocational College Students' Extracurricular Reading Status and guide research [D]. Huazhong Normal University, 2008.

[5] Ning Yanyan, Wang Yan. The new reading era literature reading of College Students Survey [J]. Journal of Library, 2008, 20 (9) :133-135,157. 